\title{
Formulation and release of alaptide from cellulose-based hydrogels
}

\author{
Zbyněk Sklenár̆ ${ }^{1}$, Zuzana Vitková ${ }^{2}$, Petra Herdová2, Kateřina Horáčková3, \\ Veronika Šimunková ${ }^{2}$ \\ ${ }^{1}$ Charles University in Prague, $1^{\text {st }}$ Faculty of Medicine, Institute of Pharmacology, \\ Prague, Czech Republic \\ ${ }^{2}$ Comenius University Bratislava, Faculty of Pharmacy, Department of Galenic Pharmacy, \\ Bratislava, Slovakia \\ ${ }^{3}$ University of Veterinary and Pharmaceutical Sciences Brno, Faculty of Veterinary Medicine, \\ Brno, Czech Republic \\ Received October 24, 2011 \\ Accepted April 11, 2012
}

\begin{abstract}
The modern drug alaptide, synthetic dipeptide, shows regenerative effects and effects on the epitelisation process. A commercial product consisting of $1 \%$ alaptide hydrophilic cream is authorised for use in veterinary practice. This study focuses on the formulation of alaptide into semi-synthetic polymer-based hydrogels. The aim of the present study is to prepare hydrogels and to evaluate the liberation of alaptide from hydrogels. The hydrogels were prepared on the basis of three gel-producing substances: methylcellulose, hydroxyethylcellulose and hydroxypropylcellulose. To enhance the drug release from hydrogel humectants, glycerol, propylene glycol and ethanol in various concentrations were evaluated. The permeation of the alaptide from gels into the acceptor solution was evaluated with the use of the permeable membrane neprophane. The amount of drug released from prepared hydrogels was determined spectrophotometrically. Hydrogels with optimal alaptide liberation properties were subjected to the study of rheological properties in the next phase. The optimal composition of hydrogel as established in this study was $1 \%$ alaptide $+3 \%$ hydroxyethylcellulose with the addition of $10 \%$ glycerol as humectant. Due to the advantageous properties of hydrogels in wounds, alaptide could be incorporated into a hydrogel base for use in veterinary medicine.
\end{abstract}

Epitelisation, gel-producing substance, humectant, methylcellulose, hydroxyethylcellulose, hydroxypropylcellulose

Hydrogel research increased significantly in the last decades; due to their properties, hydrogels are widely used as suitable bases of preparations in human and veterinary medicine. The properties of hydrophilic gels, or hydrogels, are significantly different from those of ointments and creams. Hydrogels are usually formed by hydrophilic polymers which under certain conditions and polymer concentrations create a gel with a high percentage of water. They can additionally contain glycerol or propylene glycol as humectants and ethanol as an antimicrobial agent. Hydrogels create a smooth film that adheres well, can be removed easily and exhibits a cooling effect. The active substances have been dispersed in hydrogels (dissolved, suspended or emulsified). The base with the incorporated active ingredient must have suitable properties, especially biocompatibility and chemical, microbiological and physical stability (Bronaugh and Maibach 2001).

Peptide drugs are becoming an essential part of modern therapy. Beside their therapeutic effect they can perform the function of another non-peptide drug carrier. Their reactions on changes of the $\mathrm{pH}$ milieu, biocompatibility, thermosensitivity and good mechanical properties have been reported (Galaev and Mattiasson 2008).

Alaptide is spirocyclic synthetic dipeptide, chemically prolyl-leucyl-glycine amide derivative (Nedvidková et al. 1994). Due to its positive influence on regenerative processes in various skin diseases it can be used in veterinary medicine. For a long time it has been used as a commercial $1 \%$ hydrophilic cream that stimulates granulation tissue

Address for correspondence:

PharmDr. Zbyněk Sklenár̆, Ph.D., MBA

Institute of Pharmacology

$1^{\text {st }}$ Faculty of Medicine, Charles University in Prague

Albertov 4, 12800 Prague 2, Czech Republic

Phone: +420224968104

E-mail: zbynek.sklenar@gmail.com

http://actavet.vfu.cz/ 
growth and accelerates epithelisation and wound healing processes. It has been used for skin and mucosal injury treatment (lacerations, abrasions, anal fissures, small bite injuries), burns, frostbite. It may also be used for bedsores, ulcers, sutures, claw bed injuries, chronic relapsing injuries, post-operative wounds, dog paw burns by salt in winter, etc. The usual healing time is $3-10$ days; in chronic cases the healing process takes longer. The mechanism of action of alaptide is probably due to its multiple water-binding ability and capability to improve regeneration. It is also possible to use alaptide in pregnant and nursing animals (Alaptide veterinary ointment 2011). Practice has shown that in wounds treated with alaptide, granulation tissue with marked epithelisation line rises and granulation progresses equally without hypergranulation. Thanks to the base, the wound surface remains moist, and traumatisation during rebandaging does not appear. Before application of a local topical preparation containing alaptide, it is necessary to clean the wound carefully, because the hydrophilic cream can worsen the drainage of wound secretions (Lexmaulová 2002).

Using alaptide in a hydrogel base, it is expected that drug release and absorption by the wound will be improved. A hydrogel base is more physiologically appropriate for use in wounds; it is better tolerated and more easily washed out.

The aim of this study was the incorporation of the drug alaptide into a hydrogel formulation based on semi-synthetic polymers - cellulose derivatives, and its liberation through the permeable membrane nephrophan. The composition of this membrane is very similar to that of human and animal membranes. In particular, it is commonly used in clinical practice as a dialysance membrane. The release is enhanced by glycerol, propylene glycol and ethanol, where glycerol and propylene glycol also act as humectants. Based on a previous study of alaptide-liberation from dermatological semi-solid chitosan-based preparations, it has been found that glycerol and propylene glycol can have an influence on alaptide release in dermatological semi-solid preparations (Šimunková et al. 2008). Polymer concentrations have been chosen on the basis of previous experiments with drug liberation and rheologic properties of hydrogels.

In previous works the influence of various membranes on alaptide permeation from hydrogels (Vitková et al. 2011) has been evaluated. Four membranes - cellophane, chicken skin, snake skin and intestinal wall were studied. It was found that the best permeation occurred through the intestinal wall, less through chicken skin and the least through snake skin.

\section{Materials and Methods}

\section{Chemicals}

Alaptide (ALA) - micronised form (Výzkumný ústav pro farmacii a biochemii -VÚFB, Czech Republic), ethanol 96\% (V/V) (ETH) (Ethanolum 96\% SL 1 - Liehovary, Leopoldov, Slovakia), glycerol 85\% (GLY) (Galvex spol. s.r.o., Banská Bystrica, Slovakia), hydroxyethylcellulose - Natrosol 250 HR (HEC) (Aqualon, USA), hydroxypropylcellulose - Klucel MCS (HPC) (Aqualon, USA), lactic acid (Lachema, o. p., Brno, Czech Republic), methylcellulose (MC) (Aqualon, USA), preservative agent - Sepicide HBR (Sep. HBR) (SEPPIC, Paris, France; composition: butyl p-hydroxybenzoate, ethyl p-hydroxybenzoate, sodium methyl p-hydroxybenzoate and propyl p-hydroxybenzoate in phenoxyethanol), propylene glycol (PPG) (Merck, Darmstadt, Germany), purified water (Aqua purificata SL 1- FaF UK, Bratislava, Slovakia), sodium chloride (Centrachem, Switzerland).

\section{Equipment}

Analytic scales - Kern \& Sohn GmbH (Germany), electric mixer - VEB ML W Prüfgeräte - Werk (Germany), Viskotester VT 500 - Haake Mess-Technik GmbH (Germany), pH meter - WTW Weilheim (Switzerland), spectrophotometer - Philips Pye Unicam (Great Britain), permeation equipment, permeation membrane (Nephrophan) - VEB Filmfabrik Wolfen (Germany).

\section{Hydrogel composition}

Gels based on three semi-synthetic cellulose polymers were prepared containing 2\% methylcellulose, $3 \%$ hydroxyethylcellulose or $2.5 \%$ hydroxypropylcellulose with suspended alaptide at a $1 \%$ concentration. Humectant addition in single hydrogels was 5\% PPG, 10\% GLY and $15 \%$ ethanol.

Drug liberation and content determination

Drug liberation from hydrogel was evaluated 7 and 14 days after preparation in 6 parallel evaluations. 
Table 1. Composition of hydrogels containing $1 \%$ of alaptide

\begin{tabular}{|c|c|c|c|}
\hline & PPG & GLY & ETH \\
\hline \multirow{9}{*}{$2 \% \mathrm{MC}$} & $5 \%$ & - & - \\
\hline & $10 \%$ & - & - \\
\hline & $15 \%$ & - & - \\
\hline & - & $5 \%$ & - \\
\hline & - & $10 \%$ & - \\
\hline & - & $15 \%$ & - \\
\hline & - & - & $5 \%$ \\
\hline & - & - & $10 \%$ \\
\hline & - & - & $15 \%$ \\
\hline \multirow{9}{*}{$2.5 \% \mathrm{HPC}$} & $5 \%$ & - & - \\
\hline & $10 \%$ & - & - \\
\hline & $15 \%$ & - & - \\
\hline & - & $5 \%$ & - \\
\hline & - & $10 \%$ & - \\
\hline & - & $15 \%$ & - \\
\hline & - & - & $5 \%$ \\
\hline & - & - & $10 \%$ \\
\hline & - & - & $15 \%$ \\
\hline \multirow{9}{*}{$3 \%$ HEC } & $5 \%$ & - & - \\
\hline & $10 \%$ & - & - \\
\hline & $15 \%$ & - & - \\
\hline & - & $5 \%$ & - \\
\hline & - & $10 \%$ & - \\
\hline & - & $15 \%$ & - \\
\hline & - & - & $5 \%$ \\
\hline & - & - & $10 \%$ \\
\hline & - & - & $15 \%$ \\
\hline
\end{tabular}

PPG - propylene glycol, GLY - glycerol, ETH - ethanol, MC methylcellulose, HPC - hydroxypropylcellulose, HEC - hydroxyethylcellulose
Chambers - donor part contained $3 \mathrm{~g}$ of gel, acceptor part $20 \mathrm{ml}$ of saline $(0.9 \%$ sodium chloride in purified water). Samples were temperated to $39^{\circ} \mathrm{C} \pm 0.2^{\circ} \mathrm{C}$. Although the skin temperature is lower than the body temperature, for the first experiments the body temperature was chosen. The skin temperature can be more variable according to blood perfusion. Samples were collected during $3 \mathrm{~h}-$ after 15 , $30,45,60,90,120$ a $180 \mathrm{~min}$. Alaptide content was determined spectrophotometrically at $\lambda$ $=220 \mathrm{~nm}$. Measurement results 14 days after preparation can be seen in Figs 1-3.

Flow properties of hydrogels determination

Hydrogel rheological properties were determined on a rotational viscometer at a temperature of $39 \pm 0.2{ }^{\circ} \mathrm{C}$. Every $10 \mathrm{~s}$, the torque value was recorded. The measurement was made from degree 1 to 10 and back. Determination was made at 7 and 14 days after preparation. Figs 4-6 present the results of 14 days after preparation. Study of rheological properties at a lower temperature is the subject of further research.

\section{Determination of the $\mathrm{pH}$ value} of hydrogels

The $\mathrm{pH}$ value was observed 7 and 14 days after preparation on a $\mathrm{pH}$ meter calibrated with two reference buffers - phtalate buffer with pH $4 \pm 0.02$ and borate buffer with $\mathrm{pH} 9 \pm 0.02$ at $39 \pm 0.2^{\circ} \mathrm{C}$.

\section{Results}

According to results of liberation from HEC (Fig. 1) it has been found that the best release of the drug ALA is from the gel-forming base of $3 \% \mathrm{HEC}$ with the addition of $10 \% \operatorname{GLY}(47.2 \%)$.

Using 5\% and $15 \%$ concentrations of GLY in gel, the liberation was slower. Using PPG the highest percentage of released ALA (41.5\%) was from gel with $10 \%$ PPG. In the case of ethanol the highest drug amount (39.6\%) was released by a content of $15 \%$ ethanol.

Based on the liberating profile from HPC (Fig. 2) it has been found that the best ALA release was from hydrogel with 2.5\% HPC and 5\% PPG (46.8\%). Concentration increase of this humectant caused a decrease in released ALA. Using GLY, the highest percentage of the drug $(45.8 \%)$ was released in a base containing $10 \%$ GLY. In the case of ethanol the highest drug amount (41.6\%) was released by a content of $5 \%$ ethanol.

The last base used was MC (Fig. 3). The drug ALA releases preferably from gel with $2 \%$ $\mathrm{MC}$ and $15 \%$ PPG (44.8\%). A lower percentage of released drug was found using $15 \%$ ethanol $(42.7 \%)$. The addition of $15 \%$ GLY decreased the percentage of released drug to $38.5 \%$. Further decrease of humectant concentration in gel based on MC slowed the drug release.

Based on liberation results, the most suitable hydrogel bases with the best ALA release were chosen and flow properties were determined. Hydrogel with 3\% HEC and 10\% GLY (Fig. 4) showed the non-Newton time-dependent thixotropic character of this system. 


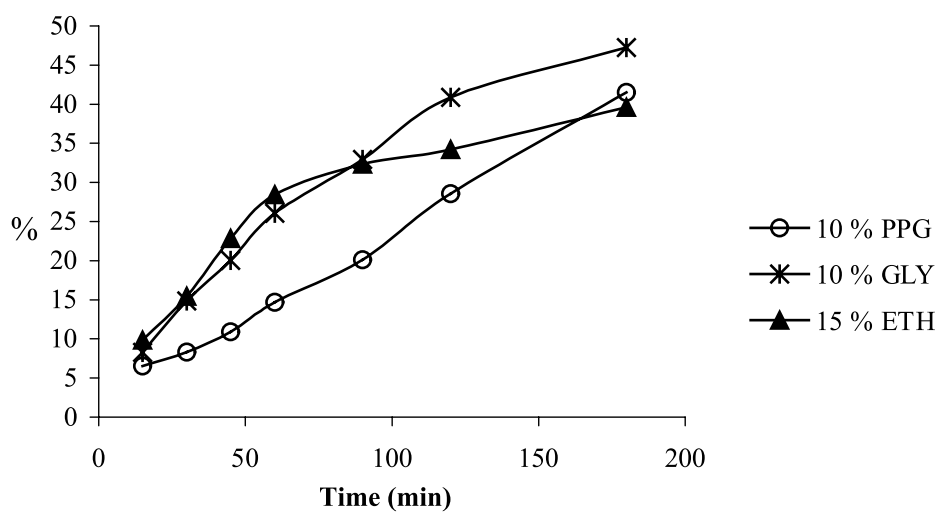

Fig. 1. Liberation of alaptide from hydroxyethylcellulose $3 \%$ hydrogel with the addition of humectant. PPG - propylene glycol, GLY - glycerol, ETH - ethanol

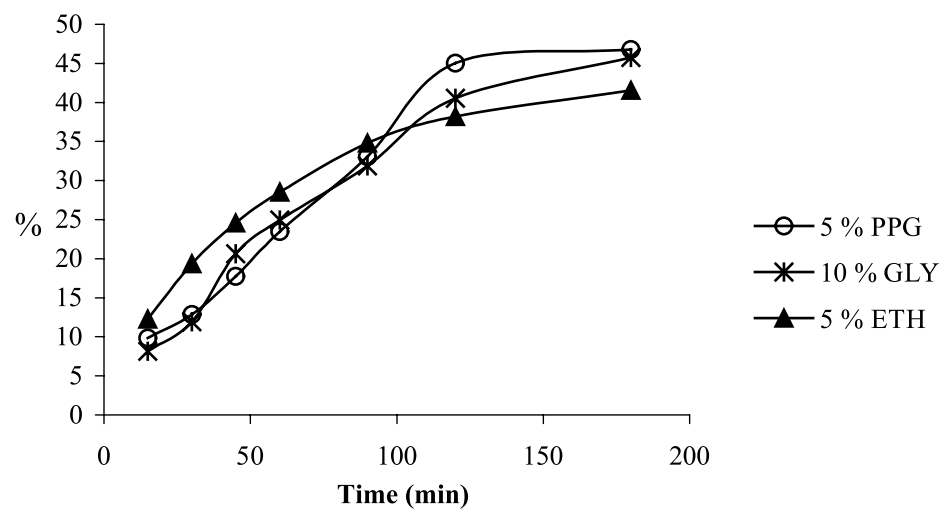

Fig. 2. Liberation of alaptide from hydroxypropylcellulose $2.5 \%$ hydrogel with the addition of humectant.

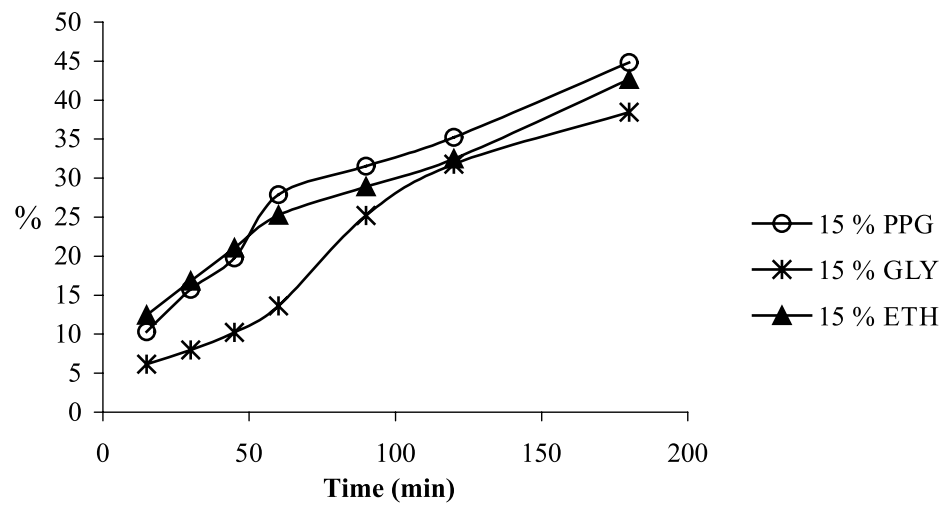

Fig. 3. Liberation of alaptide from methylcellulose $2 \%$ hydrogel with the addition of humectant. 


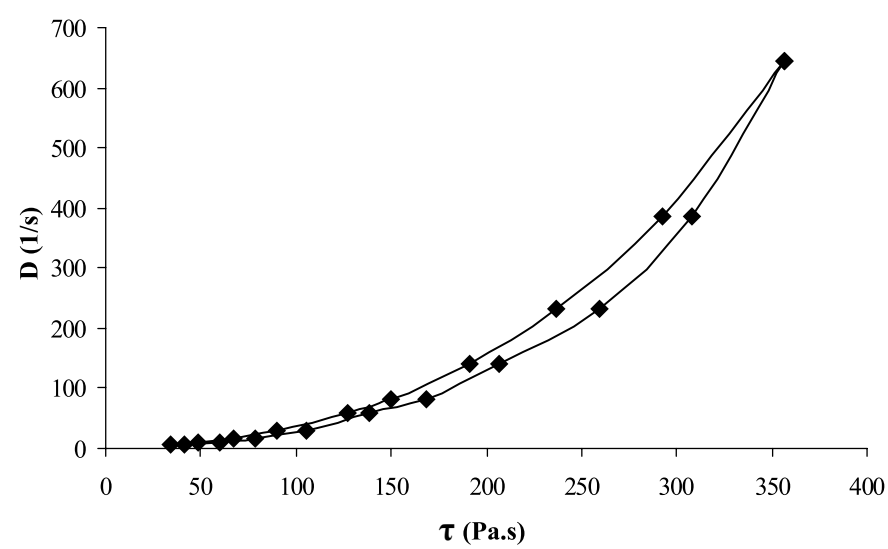

Fig. 4. Gel rheology performance of $3 \%$ hydroxyethylcellulose hydrogel with alaptide and $10 \%$ glycerol. $\mathrm{D}$ - share rates $(1 / \mathrm{s}), \tau$ - tangential tension (Pa.s)

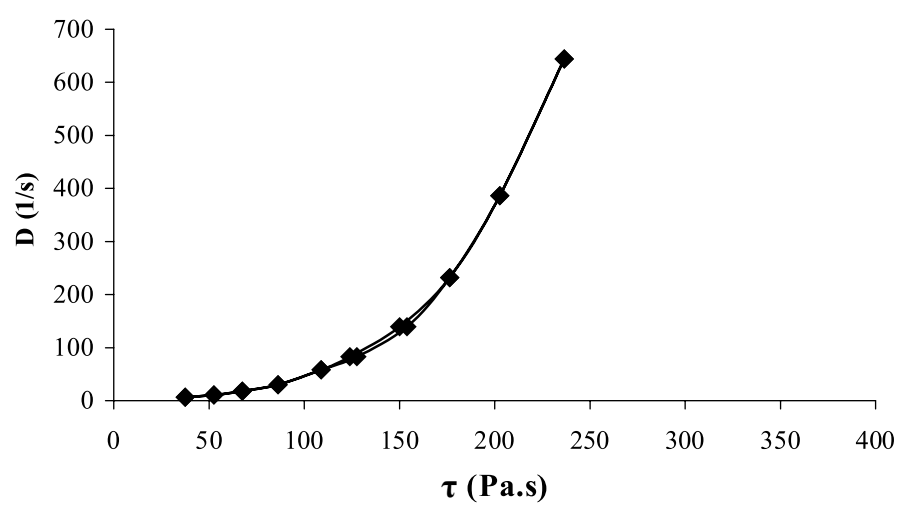

Fig. 5. Gel rheology performance of $2.5 \%$ hydroxypropylcellulose hydrogel with alaptide and $5 \%$ propylene glycol.

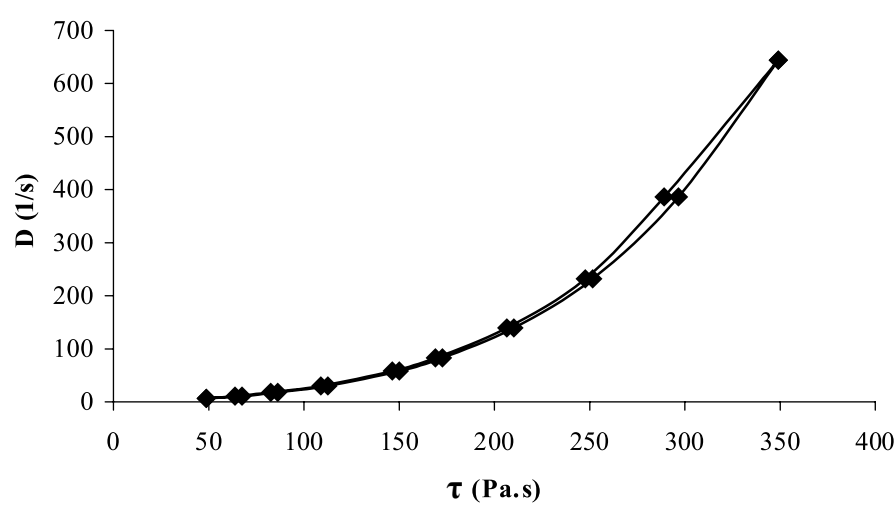

Fig. 6. Gel rheology performance of $2 \%$ methylcellulose hydrogel with alaptide and $15 \%$ propylene glycol. 
Hydrogel with 2\% MC and 15\% PPG, and 2.5\% HPC hydrogel with 5\% PPG showed pseudoplastic, time-non-dependent flow (Figs 5, 6).

The $\mathrm{pH}$ values of gels had practically no difference at 7 and 14 days after preparation. The $\mathrm{pH}$ value of hydrogel with $3 \%$ HEC and $10 \%$ GLY is determined to be $\mathrm{pH} 5.8$, hydrogel with $2 \% \mathrm{MC}$ and $15 \% \mathrm{PPG} \mathrm{pH} 5.2$ and hydrogel with 2.5\% HPC and 5\% PPG pH 4.4.

\section{Discussion}

In previous studies (Šimunková 2008), higher amount of released ALA from hydrogel compared to creams was found. The drug is released from hydrogel base easily and is absorbed faster. A hydrogel base is more physiologically appropriate for use in wounds; it is better tolerated and more easily washed out.

A gel-forming base itself can have significant influence on the liberation from the formulation. Comparing the liberation profiles of ALA from chitosan-based gels (Šimunková 2008) and cellulose-based gels, higher amount of released ALA from cellulose-based gels was found.

Optimal drug release can be reached by the choice of an appropriate cellulose derivative and a suitable humectant concentration. Compared to chitosan hydrogels (Šimunková 2008), the alaptide liberation from cellulose-based hydrogels can be achieved using lower humectant addition (5\%). A bigger amount of the drug can be released if a suitable combination of cellulose derivatives and humectant concentration is used. The amount is higher than that released of chitosan-based hydrogels, the most suitable hydrogel for alaptide release is a base containing 3\% hydroxyethylcellulose with $10 \%$ glycerol. This gel has shown the most suitable thixotropic system properties.

The $\mathrm{pH}$ values of cellulose-based hydrogels were higher ( $\mathrm{pH} 5.5$ ) than those of chitosanbased hydrogels ( $\mathrm{pH} 4.5$ ); higher value has been recommended for skin application. Higher availability and lower costs are another advantage of cellulose-based hydrogels compared to chitosan-based gels. For these reasons the use of cellulose-based hydrogels seems to be an advantage for veterinary practice.

\section{Acknowledgements}

This research has been supported by a grant VEGA No 1/0024/11 and grant FaF Univerzity Komenského, Bratislava 8/2012.

The authors gratefully acknowledge Nataša Lekić MPharm, B.Sc., for proofreading the manuscript.

\section{References}

Alaptid veterinary ointment. Available at: http://www.bioveta.cz/cs/veterinarni-divize/pripravky/novinky-promala-zvirata/alaptid.html. Accessed September 15, 2011

Bronaugh RL, Maibach HI 2001: Topical absorption of dermatological products. Marcel Dekker, Inc., New York, $516 \mathrm{p}$

Galaev I, Mattiasson B 2008: Smart polymers, applications in biotechnology and biomedicine. CRC Press, Taylor \& Francis Group, Boca Raton, $428 \mathrm{p}$

Lexmaulová L 2002: Použití Alaptidu při léčbě ran u malých zvířat (Alaptide used in the wound treatment in small animals). Veterinářství 52: 330-332

Nedvidkova J, Kasafírek E, Nedvídek J, Pacák K, Schreiber V 1994: An analog of MIF, alaptide: effect on serum prolactin, dopamine receptors and growth of rat adenohypophysis. Endocr Res 20: 39-46

Šimunková V, Vitková Z, Potúčková M, Tichý E 2008: Possible effects on the liberation of alaptid from dermal semisolid preparations. Čes Slov Farm 57: 275-277

Vitková Z, Simunková V, Herdová P, Žabka M 2011: Influence of membranes on alaptid permeation from hydrogels. Čes Slov Farm 60: 132-136 